\title{
Processos de ensino-aprendizagem de Língua Inglesa no Ensino Fundamental
}

\section{English teaching and learning processes for Elementary Education}

\author{
Procesos de enseñanza y aprendizaje de Lengua \\ Inglesa en la Enseñanza Elemental
}

Cristielaine Aparecida Alves de Souza ${ }^{1}$

Marisa Irene Siqueira Castanho ${ }^{1}$

DOI: http://dx.doi.org/10.20435/serie-estudos.v23i48.1092

\begin{abstract}
Resumo: A pesquisa teve como objetivos realizar levantamento e analisar publicações em periódicos sobre os processos de ensino-aprendizagem em inglês no ensino fundamental, em periódicos indexados na base Google Scholar e SciELO (Scientific Electronic Library Online). As análises se guiaram pela teoria sociointeracionista e pelas diretrizes do ensino de segunda língua. Os artigos analisados são do período de 2012 a 2016 de periódicos de relevância das áreas de línguas na interface com a psicologia da educação e possibilitaram organizar as informações com incidência nas subtemáticas Interação nas ações pedagógicas, Elementos da linguagem e linguísticos, Material didático e Recursos tecnológicos. Esse levantamento é ilustrativo do baixo interesse no estudo de processos de ensino-aprendizagem de inglês no ensino fundamental. Considera-se a relevância da temática e a necessidade da continuidade de pesquisas que possam evidenciar o interesse da comunidade acadêmica e das políticas públicas no letramento dos alunos do ensino fundamental.
\end{abstract}

Palavras-chave: processo ensino-aprendizagem; ensino de Língua Inglesa; sociointeracionismo.

\begin{abstract}
This research had as subject a survey and bibliographical analysis of publications in periodicals, regarding English teaching and learning process in Elementary Education, in journals indexed on the bases Google Scholar and SciELO site (Scientific Electronic Library Online) databases. The theoretical framework of cultural-historical and the guidelines of teaching a second language conducted the analysis. The analyzed articles are from 2012 to 2016 of relevant language and linguistic journals for the academic community with psychological education interface and enabled to organize the information with incidence to the subthemes: Interaction in the pedagogical actions, Elements of the language and linguistic, Didactic material and Technological resources. This survey illustrates the low interest in the study of English teaching and learning process in elementary school. It is considered the relevance of the theme and the needs for further research might demonstrate the interest of the academic community and public policies in the literacy of elementary school students.
\end{abstract}

Keywords: teaching-learning process; English Language teaching; sociointeractionism.

${ }^{1}$ Centro Universitário Fieo (UNIFIEO), Sorocaba, São Paulo, Brasil. 
Resumen: Una investigación realizada con objetivos de levantamiento y análisis de publicaciones en los periódicos sobre los procesos de enseñanza-aprendizaje en la lengua inglesa no ensino elemental, en los periódicos indexados en la base Google Scholar e SciELO, Esta pesquisa, "Ensino de Inglés y Ensino Fundamental" y "Proceso enseñanza y aprendizaje del Inglés". Como análises se guiaram por el aporte teórico del socio-interacionismo y por las orientaciones del sistema de segunda lengua. Los artículos analizados son el período de 2012 a 2016 de periódicos de relevancia para una comunidad acadêmica, las áreas de idiomas en la interfaz con una psicología de la educación. Se seleccionaron diez artículos en cinco periódicos y como análises de posibilidades. Organizaciones con información sobre las subtemáticas, Elementos didácticos y lingüísticos, Material didáctico y recursos tecnológicos. Este levantamiento, aunque no exaustivo, es ilustrativo de bajo interés, no hay estudio de procesos de enseñanza-aprendizaje de la lengua inglesa, por ausencia de publicaciones sobre el tema en periódicos de educación y psicología. Considera-se una relevancia de la temática y una necesidad de la continuidad de las investigaciones que evidencian el interés de la comunidad académica y las políticas públicas.

Palabras clave: proceso enseñanza y aprendizaje; enseñanza de La Lengua Inglesa; sócio-interacionismo.

\section{INTRODUÇÃO}

Este artigo tem como objetivos apresentar os resultados de levantamento de artigos publicados em periódicos na área de Letras e Linguística Aplicada na interface com a Psicologia da Educação acerca de práticas utilizadas nos processos de ensino-aprendizagem de língua inglesa no ensino fundamental e analisar os aportes teóricos de base utilizados pelos autores dos artigos selecionados.

Esta pesquisa tem como pressuposto teórico a abordagem sociointeracionista com base em Vigotsky, para quem os processos de ensino-aprendizagem acontecem nas interações entre os sujeitos envolvidos com foco na mediação instrumental e ou social na mobilização do sujeito em direção ao conhecimento.

Para Daniels (2003) a mediação é um importante conceito que trata das interações pelas quais os sujeitos influenciam e são influenciados por fatores sociais, culturais e históricos presentes nos contextos em que vivem e é a base fundamental do sociointeracionismo. As mediações podem ser de três tipos: 1ํ) ferramentas materiais representadas pelos artefatos; 2ㅇ) ferramentas psicológicas, combinação de instrumento e signo e 3ㅇ) outros seres humanos responsáveis pela transmissão pela linguagem e comunicação do conhecimento desenvolvido culturalmente.

Os processos de mediação e interação podem ser entendidos quando retomamos os conceitos de zona de desenvolvimento proximal (ZDP) e zona de desenvolvimento real (ZDR). A ZDP é a distância entre o nível de desenvolvimento 
real, aquilo que se consegue aprender sozinho, pois o conhecimento de algo já foi internalizado, e o nível de ira.

É justamente na zona de desenvolvimento proximal que a aprendizagem ocorre, e a mediação é importante neste processo, bem como o método e os instrumentos utilizados. No processo de escolarização, entender o funcionamento do desenvolvimento humano por essa via, pode nos conduzir a práticas pedagógicas facilitadoras da aprendizagem (VYGOTSKI, 1991). Essas práticas podem ser observadas no momento da aprendizagem durante o processo de mediação que pode ser entre pares, sujeito e computador, professor e aluno, sujeito e a brincadeira,

Dessa forma, os resultados da pesquisa foram analisados buscando aproximações das bases teóricas referenciadas ou citadas nos artigos sobre as práticas utilizadas na disciplina de Língua Inglesa para estudos de processos de ensino-aprendizagem no Ensino Fundamental, com a abordagem sociointeracionista de Vigotsky.

Segundo a teoria de desenvolvimento e aprendizagem sociointeracionista, o ser humano se desenvolve à medida que interage com o meio em que vive. Essa interação se dá através das ações físicas e mentais sobre o objeto do conhecimento. Tais pressupostos estão presentes na Lei n. 9.394, de Diretrizes e Bases Educação Nacional (LDB) (BRASIL, 1996) e nos Parâmetros Curriculares Nacionais (BRASIL, 1998). Como faz parte diversificada da Base Curricular Comum, obedecendo ao artigo 26 da LDB, "o ensino de línguas estrangeiras deve atender às características regionais e locais da sociedade, da cultura, da economia e da clientela" (BRASIL, 1996). Ou seja, deve levar em consideração os aspectos presentes no meio social e cultural dos alunos.

Dentro de um sistema formal de ensino, fica difícil caracterizar o perfil do aluno que inicia o ensino de língua estrangeira no 6 o ano do ensino fundamental, uma vez que as circunstâncias para essa análise podem ser diversas, como: levar em conta os aspectos afetivo-emocionais do período em que o aluno ingressa nesse ciclo, visto que tradicionalmente é considerado um período de transição; os diferentes níveis de conhecimento da língua materna; e os diferentes níveis em relação à familiaridade com a língua estrangeira.

Embora seja relevante considerar as características do grupo social nos processos de ensino e aprendizagem de línguas estrangeiras dentro da escola, o ensino da língua inglesa se deve muito à globalização, principalmente após a 
criação dos vários blocos e grupos econômicos que surgiram e se fortificaram no final do século XX e início do século XXI, como União Europeia, NAFTA, APEC, BRICS, IBAS, G 7, G 8 e G 20. A globalização, que é o estreitamento das relações econômicas, sociais e culturais entre os países, tornou a língua inglesa a língua oficial para as comunicações pelo fato de os países com maior poder econômico e tecnológico concentrarem maior influências sobre os demais.

Segundo Delors (DELORS, 2012), em relatório da Comissão Internacional para Educação para o século XXI da Organização das Nações Unidas para a Educação, Ciência e Cultura (UNESCO), a aprendizagem de línguas de grande difusão deve acontecer no âmbito escolar junto com a aprendizagem da língua materna para que permita oportunidades de intercâmbio cultural e maior mobilidade entre as populações. A diversidade linguística, como no caso do Brasil, com suas regiões com características de identidade e linguísticas diversificadas, não deve ser um obstáculo à comunicação, mas uma fonte de enriquecimento entre os diferentes grupos humanos, sendo a globalização um fator positivo para o aprendizado de línguas estrangeiras e meio de subsistência num mundo em constante evolução.

Dados de pesquisa do British Council (2013) mostram que o idioma inglês tem relevância internacional, pois dos 77 países analisados, 91\% têm o inglês como língua para comunicação nos negócios internacionais. Outro relatório (BRITISH COUNCIL, 2015) aponta que os índices de proficiência da língua inglesa da população brasileira são muito baixos. O ensino é focado nas estruturas gramaticais, tradução e a escrita mais trabalhada que a oralidade devido à preocupação de resultados nos vestibulares.

Para o Education First (EF EPI, 2015), o nível de proficiência em inglês no Brasil melhorou muito desde $2014^{2}$, passando para o 7 ㅇ lugar em relação aos países da América Latina e 410 lugar entre os 70 países analisados. Esse resultado parece decorrer de iniciativas e investimentos lançados a partir desse mesmo ano, para melhorar a qualidade do ensino de inglês em escolas públicas. Por meio da

\footnotetext{
${ }^{2}$ Data em que foi sancionada a Lei n. 13.005 de junho de 2014 que estabelece o Plano Nacional de Educação (PNE) e define os rumos da educação brasileira de 2014 a 2024 (BRASIL, 2014). O plano decenal, iniciado em 1993, se deu em decorrência da Conferencia Mundial de Educação para Todos de 1990, que define novas abordagens sobre as necessidades básicas de aprendizagem, as metas a serem atingidas relativamente à educação básica e os compromissos dos Governos e outras entidades participantes (UNESCO, 1990).
} 
capacitação de professores, o impacto dos programas para melhoria da qualidade de ensino começa a atingir as crianças do ensino fundamental.

Ainda sobre capacitação no idioma inglês, em 2013 (EF EPI, 2015), o Ministério da Educação criou o "Inglês Sem Fronteiras" ${ }^{3}$ com o intuito de preparar estudantes universitários para graduações em países anglo-saxônicos. O programa já capacitou estudantes em mais de 120 universidades públicas de todo o país. Antes da Copa do Mundo de 2014 e dos Jogos Olímpicos do Rio 2016, os ministérios de educação e turismo do Brasil lançaram juntos o Pronatec Turismo em 2012 (EF EPI, 2015), oferecendo aulas de inglês gratuitas para mais de 150.000 profissionais de turismo em 120 cidades.

No entanto, se considerarmos que, desde a década de 90, data da Conferência de Jomtien (UNESCO, 1990) e, mais precisamente em 1993, quando foi assinada a Declaração de Nova Delhi sobre Educação para Todos, esforços vêm sendo realizados em prol da melhoria da qualidade de ensino, mas ainda não foram plenamente bem sucedidos, o que indica a necessidade de se repensar os processos de ensino-aprendizagem, os conteúdos e os métodos a serem desenvolvidos na educação básica.

A educação é um bem inalienável e, por meio dela, é que se proporciona aos indivíduos das sociedades o poder de enfrentarem seus problemas mais urgentes, como o combate à pobreza, aumento da produtividade, melhora das condições de vida e proteção ao meio ambiente, permitindo que assumam seu papel por direito na construção de sociedades democráticas e no enriquecimento de sua herança cultural (UNESCO, 1990).

Embora as questões metodológicas do ensino-aprendizagem de língua não devam configurar o único problema a ser enfrentado, no âmbito das práticas pedagógicas muito se pode fazer para atingir um ensino de qualidade. Segundo Rios (2003), a palavra qualidade pode trazer várias significações que podem ser boas ou más. O que se considera bom ou mal tem um caráter sócio-histórico ou socioculural, que vão desde as mudanças que ocorrem na legislação da educação para o ensino de línguas estrangeiras e até mesmo nas diferentes propostas

\footnotetext{
${ }^{3}$ Programa de aperfeiçoamento da língua inglesa de maneira rápida e eficiente para jovens candidatos a bolsas de estudo do Programa Ciência sem Fronteiras.
} 
metodológicas que abrem espaços para práticas de ensino em sala de aula que respeitem às diferenças ideológicas, étnicas e culturais. Daí o interesse pela revisão de literatura proposta neste estudo sobre a temática do ensino de língua inglesa.

\section{MÉTODO}

O levantamento de publicações sobre o ensino de língua inglesa e suas bases teóricas foi realizado pela busca em periódicos de maior relevância na comunidade acadêmica, de extratos A, segundo a Plataforma Sucupira Periódicos Qualis 2014. Utilizando-se de ferramentas de busca nas bases de dados do Google Scholar e do site da Scientific Electronic Library Online (SciELO), foram empregados os descritores: "Ensino Fundamental e Inglês"; "Processos ensino-aprendizagem e língua inglesa", tendo sido selecionados 10 artigos em cinco periódicos, relativos ao período de 2012 a 2016,

Os artigos foram listados de forma ordenada por ano de publicação e organizados por: 1) título; 2) autores e filiação institucional; 3) dados do periódico; 4) palavras-chave; 5) resumo. Essa organização gerou gráficos com incidência de publicações por ano e área, que foram confrontadas com as bases Scimago Journal Rank (SJR), Domínios de Linguagem e Acta Scientiarum and Culture, que possibilitaram averiguar as tendências de publicações nas várias áreas de conhecimento, tanto em âmbito nacional como internacional.

Num segundo momento, foi feita a análise de conteúdo (MORAES, 1999; BARDIN, 1977) por meio da leitura dos títulos, resumos e palavras-chave para o reconhecimento de subtemáticas abordadas e referenciais teóricos explicitados. Por fim, os conteúdos foram interpretados buscando-se uma aproximação com a abordagem sociointeracionista.

\section{RESULTADOS E DISCUSSÕES}

Os 10 artigos selecionados encontram-se listados no Quadro 1, dos quais oito são relacionados à área de Linguística Aplicada e dois são de Inglês, Literaturas e Estudos Culturais. Quanto aos cinco periódicos em que foram localizados, os artigos são apresentados em breve descrição. 
Quadro 1 - Relação completa dos artigos selecionados

\begin{tabular}{|c|c|c|c|c|c|c|}
\hline n. & Título & $\begin{array}{l}\text { Autor e filiação } \\
\text { institucional }\end{array}$ & \multicolumn{2}{|c|}{ Periódico } & Palavras-chave & Resumo \\
\hline 1 & $\begin{array}{l}\text { A percepção de } \\
\text { jovens aprendizes } \\
\text { de segunda língua } \\
\text { em relação à } \\
\text { prática de revisão } \\
\text { por pares em } \\
\text { produção escrita }\end{array}$ & $\begin{array}{l}\text { Daniele Blos } \\
\text { Bolzan; } \\
\text { Karen Pupp } \\
\text { Spinassé - } \\
\text { UFRGS }\end{array}$ & $\begin{array}{l}\text { Ilha do } \\
\text { Desterro }\end{array}$ & $\begin{array}{l}\text { v. } 69 \text {, } \\
\text { n. } 1,2016 \\
\text { - UFSC }\end{array}$ & $\begin{array}{l}\text { Revisão } \\
\text { por Pares; } \\
\text { Atividade } \\
\text { Colaborativa; } \\
\text { Produção } \\
\text { Escrita }\end{array}$ & $\begin{array}{l}\text { Este artigo apresenta dados de uma pes- } \\
\text { quisa que propôs a prática de revisão por } \\
\text { pares de produção escrita em inglês a um } \\
8^{\circ} \text { ano do Ensino Fundamental de uma es- } \\
\text { cola com currículo bilíngue no sul do Brasil. } \\
\text { A pesquisa investiga a atividade colabora- } \\
\text { tiva em que os alunos se engajam quando } \\
\text { revisam as produções de seus pares e o } \\
\text { efeito que essas revisões tiveram na re- } \\
\text { escrita dos textos. O recorte apresentado } \\
\text { neste artigo analisa as expectativas dos } \\
\text { aprendizes antes, bem como sua avaliação } \\
\text { depois da prática de revisão por pares.Os } \\
\text { dados foram obtidos através de questioná- } \\
\text { rios e entrevistas, e o método utilizado foi } \\
\text { o misto(análise qualitativa e quantitativa). } \\
\text { Os resultados mostram a abertura dos } \\
\text { participantes a essa prática pedagógica e } \\
\text { ao trabalho colaborativo, e demonstram o } \\
\text { seu otimismo em relação à possibilidade } \\
\text { de melhoria dos seus textos após a revisão } \\
\text { do colega. Os dados também trazem con- } \\
\text { tribuições em relação ao papel do profes- } \\
\text { sor e ao uso da segunda língua na revisão } \\
\text { por pares. }\end{array}$ \\
\hline 2 & $\begin{array}{l}\text { Ensinar e } \\
\text { aprender língua } \\
\text { estrangeira / } \\
\text { adicional na } \\
\text { escola: a relação } \\
\text { entre perspectivas } \\
\text { críticas e uma ex- } \\
\text { periência prática } \\
\text { localizada }\end{array}$ & $\begin{array}{l}\text { Viviane Pires } \\
\text { Viana Silvestre } \\
\text { - UEG }\end{array}$ & $\begin{array}{l}\text { Revista } \\
\text { Brasileira } \\
\text { de } \\
\text { Linguística } \\
\text { Aplicada }\end{array}$ & $\begin{array}{l}\text { v. } 15, \mathrm{n} . \\
1,2015- \\
\text { UFMG }\end{array}$ & \begin{tabular}{l|} 
\\
Língua \\
estrangeira/ \\
adicional; \\
Ensino e \\
aprendizagem; \\
Perspectivas \\
críticas; Prática \\
localizada \\
\end{tabular} & $\begin{array}{l}\text { Este texto reflete sobre a possível rein- } \\
\text { terpretação de fundamentos globais de } \\
\text { perspectivas críticas de ensinar e apren- } \\
\text { der língua estrangeira/adicional, em um } \\
\text { contexto local de escola pública. As ações } \\
\text { pedagógicas analisadas foram desenvolvi- } \\
\text { das nas aulas de inglês de duas turmas de } \\
\text { oitavo ano do Ensino Fundamental e fize- } \\
\text { ram parte das atividades de um subprojeto } \\
\text { do Programa Institucional de Bolsas de } \\
\text { Iniciação à Docência (Pibid). O estudo } \\
\text { aponta para o papel do agenciamento do- } \\
\text { cente, para que expectativas contemporâ- } \\
\text { neas para o ensino de língua estrangeiral } \\
\text { adicional (SCHLATTER; GARCEZ, 2012; } \\
\text { MONTE MÓR, 2013a, 2013b) sejam viven- } \\
\text { ciadas no contexto escolar. }\end{array}$ \\
\hline
\end{tabular}




\begin{tabular}{|c|c|c|c|c|c|c|}
\hline n. & Título & $\begin{array}{c}\text { Autor e filiação } \\
\text { institucional }\end{array}$ & \multicolumn{2}{|c|}{ Periódico } & Palavras-chave & Resumo \\
\hline 3 & $\begin{array}{l}\text { Discurso sobre } \\
\text { ensino de língua } \\
\text { inglesa e gramá- } \\
\text { tica sistêmico- } \\
\text {-funcional }\end{array}$ & $\begin{array}{l}\text { Ederson } \\
\text { Henrique de } \\
\text { Souza Machado } \\
\text { - UFSM }\end{array}$ & $\begin{array}{l}\text { Domínios } \\
\text { da } \\
\text { Linguagem }\end{array}$ & $\begin{array}{l}\text { v. } 8, n . \\
1,2014- \\
\text { UFU }\end{array}$ & $\begin{array}{l}\text { Discurso; } \\
\text { Léxico- } \\
\text { gramática e } \\
\text { Ensino de } \\
\text { Língua Inglesa }\end{array}$ & $\begin{array}{l}\text { O presente trabalho objetiva demonstrar } \\
\text { alguns elementos linguísticos que expri- } \\
\text { mem a reconfiguração da característica } \\
\text { Neoliberal presente no discurso sobre o } \\
\text { ensino de língua inglesa nas realizações } \\
\text { léxico-gramaticais em textos de estu- } \\
\text { dantes do ensino fundamental. O estudo } \\
\text { contou com o aporte teórico da Análise de } \\
\text { Discurso Crítica e do sistema de Transitivi- } \\
\text { dade da Linguística Sistêmico-Funcional. A } \\
\text { análise foi realizada sobre as respostas de } \\
\text { 402 estudantes do go ano do ensino funda- } \\
\text { mental público do sudoeste do Paraná. As } \\
\text { respostas - obtidas mediante questioná- } \\
\text { rios- eram sobre a noção de ensino de lín- } \\
\text { gua inglesa dos estudantes. Os resultados } \\
\text { apresentam que alguns elementos léxico- } \\
\text {-gramaticais marcam um "afastamento" } \\
\text { discursivo dos estudantes/enunciadores, } \\
\text { em relação ao ensino de língua inglesa, } \\
\text { representado por eles; essa relação de } \\
\text { "afastamento" é um elemento de reconf- } \\
\text { guração do aspecto Neoliberal presente } \\
\text { no discurso sobre ensino de língua inglesa } \\
\text { que se ajusta ao contexto da atividade ma- } \\
\text { terial dos estudantes investigados. }\end{array}$ \\
\hline 4 & $\begin{array}{l}\text { Avaliação (des) } \\
\text { contextualizada } \\
\text { de língua inglesa } \\
\text { no ensino funda- } \\
\text { mental - a distân- } \\
\text { cia entre teoria e } \\
\text { prática }\end{array}$ & $\begin{array}{l}\text { Welisson } \\
\text { Marques; Doris } \\
\text { Day Rodrigues } \\
\text { Marques - UFU } \\
\text { - UFTM }\end{array}$ & $\begin{array}{l}\text { Acta } \\
\text { Scientiarum. } \\
\text { Language } \\
\text { and Culture }\end{array}$ & $\begin{array}{l}\text { v. } 36, \text { n. } \\
\text { 2, p. 183- } \\
\text { 193, } 2014 \\
\text { - UEM }\end{array}$ & \begin{tabular}{|l|} 
\\
avaliação, \\
avaliação \\
contextualizada, \\
língua inglesa, \\
concepções \\
de linguagem, \\
PCNs. \\
\\
\end{tabular} & $\begin{array}{l}\text { Este trabalho efetua uma análise de ava- } \\
\text { liações com vias a observar, por um lado, } \\
\text { sua proposta teórica de contextualização } \\
\text { (dos PCNs) e, por outro, a contingência } \\
\text { de tal prática. Tomamos como corpus dez } \\
\text { avaliações do } 6^{0} \text { ao } 9^{\circ} \text { anos, aplicadas por } \\
\text { professores da rede pública de ensino de } \\
\text { Minas Gerais. Os documentos analisados } \\
\text { revelam uma ênfase nos aspectos sistêmi- } \\
\text { cos, em especial na correção gramatical, } \\
\text { por meio de exercícios objetivos e estrutu- } \\
\text { rados. Parece não haver interação com o } \\
\text { educando; as atividades são predominan- } \\
\text { temente abstratas e pouco significativas. } \\
\text { Isso pode ser reflexo da concepção de } \\
\text { linguagem que constitui esses profissio- } \\
\text { nais e norteia sua práxis, concepção essa } \\
\text { que toma a língua como um constructo } \\
\text { idealizado e desvinculado da realidade e } \\
\text { que reduz o seu ensino ao conhecimento } \\
\text { de gramática. }\end{array}$ \\
\hline
\end{tabular}




\begin{tabular}{|c|c|c|c|c|c|c|}
\hline n. & Título & $\begin{array}{c}\text { Autor e filiação } \\
\text { institucional }\end{array}$ & \multicolumn{2}{|c|}{ Periódico } & Palavras-chave & Resumo \\
\hline 5 & $\begin{array}{l}\text { Libras no ensino } \\
\text { de inglês mediado } \\
\text { pelas novas tec- } \\
\text { nologias: desafios } \\
\text { e possibilidades }\end{array}$ & $\begin{array}{l}\text { Kátia Cristina do } \\
\text { Amaral Tavares; } \\
\text { Ana Paula Pires } \\
\text { de Oliveira - } \\
\text { UFRJ }\end{array}$ & $\begin{array}{l}\text { Revista } \\
\text { Brasileira } \\
\text { de } \\
\text { Linguística } \\
\text { Aplicada }\end{array}$ & $\begin{array}{l}\text { v. } 14, \mathrm{n} . \\
4,2014 \text { - } \\
\text { UFMG }\end{array}$ & $\begin{array}{l}\text { Libras, ensino } \\
\text { de inglês, } \\
\text { escrita, } \\
\text { mediação, } \\
\text { tecnologia, } \\
\text { inclusão, } \\
\text { surdez. }\end{array}$ & $\begin{array}{l}\text { Este estudo investiga a perspectiva de } \\
\text { professores, intérpretes e alunos sobre } \\
\text { o ensino de inglês mediado pelo uso das } \\
\text { novas tecnologias e da Língua Brasileira } \\
\text { de Sinais (Libras) em uma escola pública } \\
\text { inclusiva, a fim de identificar os desafios } \\
\text { enfrentados por eles nesse contexto e } \\
\text { apontar possíveis formas de superá-los. } \\
\text { Os dados foram gerados através de ques- } \\
\text { tionários, entrevistas, grupo focal, diário de } \\
\text { pesquisa e gravação de aulas em vídeo. } \\
\text { As aulas analisadas foram ministradas } \\
\text { para uma turma de sétimo ano na sala de } \\
\text { informática. Através da análise qualitativa } \\
\text { dos dados, os desafios e as possibilidades } \\
\text { observados foram agrupados em quatro } \\
\text { núcleos de significado: (1) a mediação de } \\
\text { três línguas: Libras, português e inglês; (2) } \\
\text { a mediação do intérprete de Libras; (3) o } \\
\text { professor e o uso de Libras; (4) a mediação } \\
\text { da tecnologia. }\end{array}$ \\
\hline 6 & $\begin{array}{l}\text { Libras no ensino } \\
\text { de inglês mediado } \\
\text { pelas novas tec- } \\
\text { nologias: desafios } \\
\text { e possibilidades }\end{array}$ & $\begin{array}{l}\text { Kátia Cristina do } \\
\text { Amaral Tavares; } \\
\text { Ana Paula Pires } \\
\text { de Oliveira - } \\
\text { UFRJ }\end{array}$ & $\begin{array}{l}\text { Revista } \\
\text { Brasileira } \\
\text { de } \\
\text { Linguística } \\
\text { Aplicada }\end{array}$ & $\begin{array}{l}\text { v. } 14, \mathrm{n} . \\
4,2014 \text { - } \\
\text { UFMG }\end{array}$ & $\begin{array}{l}\text { Libras, ensino } \\
\text { de inglês, } \\
\text { escrita, } \\
\text { mediação, } \\
\text { tecnologia, } \\
\text { inclusão, } \\
\text { surdez. }\end{array}$ & $\begin{array}{l}\text { Este estudo investiga a perspectiva de } \\
\text { professores, intérpretes e alunos sobre } \\
\text { o ensino de inglês mediado pelo uso das } \\
\text { novas tecnologias e da Língua Brasileira } \\
\text { de Sinais (Libras) em uma escola pública } \\
\text { inclusiva, a fim de identificar os desafios } \\
\text { enfrentados por eles nesse contexto e } \\
\text { apontar possíveis formas de superá-los. } \\
\text { Os dados foram gerados através de ques- } \\
\text { tionários, entrevistas, grupo focal, diário de } \\
\text { pesquisa e gravação de aulas em vídeo. } \\
\text { As aulas analisadas foram ministradas } \\
\text { para uma turma de sétimo ano na sala de } \\
\text { informática. Através da análise qualitativa } \\
\text { dos dados, os desafios e as possibilidades } \\
\text { observados foram agrupados em quatro } \\
\text { núcleos de significado: (1) a mediação de } \\
\text { três línguas: Libras, português e inglês; (2) } \\
\text { a mediação do intérprete de Libras; (3) o } \\
\text { professor e o uso de Libras; (4) a mediação } \\
\text { da tecnologia. }\end{array}$ \\
\hline
\end{tabular}




\begin{tabular}{|c|c|c|c|c|c|c|}
\hline n. & Título & $\begin{array}{c}\text { Autor e fliação } \\
\text { institucional }\end{array}$ & \multicolumn{2}{|c|}{ Periódico } & Palavras-chave & Resumo \\
\hline 7 & $\begin{array}{l}\text { Produção textual } \\
\text { como um proces- } \\
\text { so em um con- } \\
\text { texto centrado no } \\
\text { produto: desafios } \\
\text { e possibilidades }\end{array}$ & $\begin{array}{l}\text { Isabela de } \\
\text { Freitas Vilas } \\
\text { Boas - UB }\end{array}$ & $\begin{array}{l}\text { Revista } \\
\text { Brasileira } \\
\text { de } \\
\text { Linguística } \\
\text { Aplicada }\end{array}$ & $\begin{array}{l}\text { v. } 14, \mathrm{n} \text {. } \\
2,2014- \\
\text { UFMG }\end{array}$ & \begin{tabular}{|l|} 
\\
\\
ensino da \\
escrita como \\
um processo; \\
ensino da \\
escrita em \\
língua materna; \\
ensino \\
de inglês \\
como língua \\
estrangeira; \\
revisão por \\
pares \\
\\
\\
\end{tabular} & $\begin{array}{l}\text { Este estudo de caso analisou a aplicabili- } \\
\text { dade de uma pedagogia para o ensino da } \\
\text { escrita como um processo em um contexto } \\
\text { de ensino de inglês como língua estrangei- } \\
\text { ra e como os estudantes reagiram e res- } \\
\text { ponderam a essa metodologia de ensino. } \\
\text { Um grupo de } 16 \text { adolescentes de nível } \\
\text { intermediário em uma instituição particular } \\
\text { de ensino de inglês foi selecionado. Foi } \\
\text { seguido um projeto pedagógico em torno } \\
\text { da escrita como um processo e as reações } \\
\text { e o desempenho dos alunos em cada um } \\
\text { dos estágios do processo foi analisado. Ao } \\
\text { mesmo tempo, investigou-se como se dá } \\
\text { o ensino da escrita na língua materna nas } \\
\text { escolas regulares dos alunos. Concluiu- } \\
\text {-se que o ensino de produção textual nas } \\
\text { escolas regulares enfoca mais o processo } \\
\text { do que o produto e que uma pedagogia } \\
\text { voltada para o processo nas aulas de in- } \\
\text { glês pode preencher lacunas deixadas nas } \\
\text { experiências dos alunos com a escrita na } \\
\text { língua materna. }\end{array}$ \\
\hline 8 & $\begin{array}{l}\text { Instanciação da } \\
\text { complexidade da } \\
\text { aprendizagem de } \\
\text { alunos e profes- } \\
\text { sores na sala de } \\
\text { aula de inglês } \\
\text { como língua } \\
\text { estrangeira }\end{array}$ & $\begin{array}{l}\text { Nayibe Rosad - } \\
\text { Uninorte }\end{array}$ & \begin{tabular}{|l} 
Revista \\
Brasileira \\
de \\
Linguística \\
Aplicada
\end{tabular} & $\begin{array}{l}\text { v. } 13, \mathrm{n} . \\
2,2013- \\
\text { UFMG }\end{array}$ & \begin{tabular}{|l|} 
\\
aprendizagem \\
de alunos; \\
aprendizagem \\
de professores; \\
complexidade; \\
princípios \\
dos sistemas \\
complexos; \\
estudo de caso \\
etnográfico; \\
ensino \\
de inglês \\
como língua \\
estrangeira. \\
\\
\end{tabular} & $\begin{array}{l}\text { Este artigo relata alguns dos resultados } \\
\text { de um estudo cujo objetivo foi interpretar } \\
\text { a aprendizagem de alunos e professores } \\
\text { que emergiram das interações geradas no } \\
\text { e além do contexto de suas salas de aula } \\
\text { inglês como língua estrangeira em uma es- } \\
\text { cola estadual em Barranquilla, Colômbia. } \\
\text { Neste estudo, uso princípios dos sistemas } \\
\text { complexos (MORIN, 1994) para compreen- } \\
\text { der os sistemas de aprendizagem de alu- } \\
\text { nos e de professores. Os dados para este } \\
\text { estudo de caso etnográfico incluem obser- } \\
\text { vações de sala de aula, entrevistas, diários } \\
\text { de aprendizagem e documentos (cadernos } \\
\text { dos alunos, folhas de exercícios, quizzes, } \\
\text { e o currículo). Um software para análise } \\
\text { qualitativa (Atlas.ti } 6.0 \text { ) foi usado para a } \\
\text { análise dos dados. Os resultados deste } \\
\text { estudo contribuem para compreender a } \\
\text { aprendizagem como um sistema complexo } \\
\text { ao abordar a aprendizagem dos alunos por } \\
\text { meio de uma perspectiva complexa, recur- } \\
\text { sivamente associada à aprendizagem dos } \\
\text { professores. }\end{array}$ \\
\hline
\end{tabular}




\begin{tabular}{|c|c|c|c|c|c|c|}
\hline n. & Título & $\begin{array}{c}\text { Autor e filiação } \\
\text { institucional }\end{array}$ & \multicolumn{2}{|c|}{ Periódico } & Palavras-chave & Resumo \\
\hline 9 & $\begin{array}{l}\text { Critical literacy in } \\
\text { the english lan- } \\
\text { guage classroom }\end{array}$ & $\begin{array}{l}\text { Clarissa } \\
\text { Menezes } \\
\text { Jordão; } \\
\text { Francisco } \\
\text { Carlos Fogaça - } \\
\text { UFPR }\end{array}$ & Delta & $\begin{array}{l}\text { v. 28, n. } \\
1,2012- \\
\text { PUC }\end{array}$ & $\begin{array}{l}\text { letramento } \\
\text { crítico, } \\
\text { cidadania, } \\
\text { ensino de } \\
\text { inglês, escolas } \\
\text { públicas }\end{array}$ & $\begin{array}{l}\text { Este artigo relata uma experiência de desen- } \\
\text { volvimento de materiais didáticos para alunos } \\
\text { de escolas públicas no sul do Brasil, em um } \\
\text { projeto financiado pela SEED - Secretaria de } \\
\text { Estado da Educação do Paraná. Os materiais } \\
\text { foram pensados como recursos a serem utili- } \\
\text { zados pelos professores de acordo com suas } \\
\text { necessidades locais, ao invés de constitúi- } \\
\text { rem-se simplesmente em um livro didático. A } \\
\text { teoria subjacente ao projeto está baseada no } \\
\text { letramento crítico e na concepção da língua } \\
\text { como discurso, ou seja, uma língua repleta } \\
\text { de valores culturais e ideológicos, os quais } \\
\text { determinam significados e estabelecem rela- } \\
\text { ções de poder entre textos, entre leitores e } \\
\text { entre textos e seus leitores, em sintonia com } \\
\text { o conceito freiriano de palavramundo - "wor(l) } \\
\text { d". Os alunos leitores são, nesse sentido, } \\
\text { coprodutores de significados e responsáveis } \\
\text { por dar sentido à realidade. Esperamos que } \\
\text { alunos e professores, que venham a utilizar } \\
\text { os materiais que elaboramos, se tornem mais } \\
\text { cientes de suas possibilidades como agentes } \\
\text { e, desse modo, pretendemos estimular um } \\
\text { sentido de cidadania ativa tanto em alunos } \\
\text { quanto em professores. }\end{array}$ \\
\hline 10 & $\begin{array}{l}\text { Ensino e aprendi- } \\
\text { zagem de língua } \\
\text { inglesa e recursos } \\
\text { tecnológicos: } \\
\text { um estudo sobre } \\
\text { os processos } \\
\text { de retroação e } \\
\text { irreversibilidade }\end{array}$ & $\begin{array}{l}\text { Larissa de } \\
\text { Sousa Silveira - } \\
\text { UFTM }\end{array}$ & $\begin{array}{l}\text { Domínios } \\
\text { de } \\
\text { Linguagem: } \\
\text { Revista } \\
\text { Eletrônica } \\
\text { de } \\
\text { Linguística }\end{array}$ & $\begin{array}{l}\text { v. } 6, \mathrm{n} . \\
\text { 2, 2012 - } \\
\text { UFU }\end{array}$ & $\begin{array}{l}\text { Língua Inglesa; } \\
\text { processo } \\
\text { de ensino e } \\
\text { aprendizagem; } \\
\text { recursos } \\
\text { tecnológicos; } \\
\text { Paradigma da } \\
\text { Complexidade }\end{array}$ & $\begin{array}{l}\text { Crystal (2003) ressalta a importância da } \\
\text { Língua Inglesa ao classificá-la como a língua } \\
\text { universal utilizada por milhões de falantes ao } \\
\text { redor do mundo. Partindo desse pressuposto, } \\
\text { propusemo-nos a pesquisar sobre o proces- } \\
\text { so de ensino e aprendizagem dessa língua } \\
\text { e a importância dos recursos tecnológicos } \\
\text { no contexto formal e informal de aprendiza- } \\
\text { gem. Objetivamos ainda entender como as } \\
\text { atitudes dos professores podem influenciar } \\
\text { de maneira negativa no desenvolvimento do } \\
\text { interesse dos alunos pela disciplina, inter- } \\
\text { rompendo o processo natural de Retroação } \\
\text { (BERTALANFFY, 1975) ao qual eles são sub- } \\
\text { metidos. Para tanto, utilizamos como base } \\
\text { teórica as premissas do Paradigma da Com- } \\
\text { plexidade (HOLLAND, 1998; DEMO, 2002). } \\
\text { Os dados foram coletados em uma escola } \\
\text { pública municipal de Uberaba/MG através } \\
\text { de observações, anotações e aplicação de } \\
\text { um questionário. Após as análises, concluí- } \\
\text { mos que a interrupção do processo tende a } \\
\text { acontecer quando o aprendiz sente a falta de } \\
\text { incentivo por parte daquele que deveria ser } \\
\text { seu maior incentivador na busca por novos } \\
\text { conhecimentos. Concluímos ainda que o edu- } \\
\text { cador deve trabalhar como um mediador para } \\
\text { auxiliar os alunos no reconhecimento das } \\
\text { novas tecnologias digitais como inerentes ao } \\
\text { processo de aquisição de conhecimento. }\end{array}$ \\
\hline
\end{tabular}


A Revista Brasileira de Linguística Aplicada é uma publicação sem fins lucrativos, de responsabilidade do Programa de Pós-Graduação em Estudos Linguísticos, área de concentração em Linguística Aplicada da Universidade Federal de Minas Gerais (UFMG). Trata-se de um periódico bianual, com avaliação por pares, o qual tem a missão de encorajar a pesquisa na área de Linguística Aplicada. Criada em 2001, a revista recebe artigos que tratam dos muitos fenômenos relacionados a problemas de linguagem da vida real e à língua em uso em contextos diversos ou à aprendizagem.

A Revista Ilha do Desterro publica, desde 1979, artigos e resenhas inéditos nas áreas de Inglês, Literatura e Estudos Culturais. Ilha do Desterro é um periódico do Programa de Pós-Graduação em Letras: Inglês e Literatura Correspondente da Universidade Federal de Santa Catarina (UFSC), com publicação quadrimestral. Sua maior missão é circular os resultados de pesquisas acadêmicas nas áreas de Inglês, Literatura e Estudos Culturais.

Domínios de Lingu@gem é uma revista eletrônica dedicada aos temas da Linguística Teórica e Aplicada, com publicação trimestral, do Instituto de Letras e Linguística da Universidade Federal de Uberlândia (UFU). Os números do primeiro e terceiro trimestre são atemáticos, os do segundo e quarto, temáticos.

Acta Scientiarum Language Culture é uma revista da Universidade Estadual de Maringá (UEM) dedicada às áreas de Letras e Linguística, publicada com periodicidade trimestral. Sua missão é viabilizar o registro público do conhecimento e sua preservação; publicar resultados de pesquisas envolvendo inovações de ideias e de propostas científicas; disseminar a informação e o conhecimento gerados pela comunidade científica e criar condições para o debate científico nas áreas de Letras e Linguística. A temática é livre nessas áreas, aceitando artigos sob as mais diversas perspectivas teóricas, metodológicas e analíticas. Na área de conhecimento dos Estudos Linguísticos, as edições reúnem contribuições que compreendem diferentes focos, dentre eles o ensino e a aprendizagem de línguas, língua e tradução, novas tecnologias e ensino de línguas, cultura e materialidades significantes, estudos do texto e do discurso e descrição linguística. No tocante à área dos Estudos Literários, a revista dedica especial atenção aos estudos envolvendo o campo literário e formação de leitores, bem como as mediações entre literatura e história assim como entre literatura e construção de identidades. 
Delta: Revista de Linguística e Linguística Aplicada é publicada desde 1985 na Pontifícia Universidade Católica de São Paulo (PUC-SP) sem interrupção. Lança anualmente dois volumes para os quais recebe contribuições da comunidade acadêmica nacional e internacional e um volume temático. Consta do Portal SciELO, a convite, desde sua fundação em 2001. Publica estudos especializados de caráter teórico ou aplicado, oriundos de qualquer área referente ao fenômeno linguístico, desde que se trate de contribuição inédita.

Na Figura 1, apresenta-se a distribuição percentual dos artigos selecionados, por ano e por periódico.

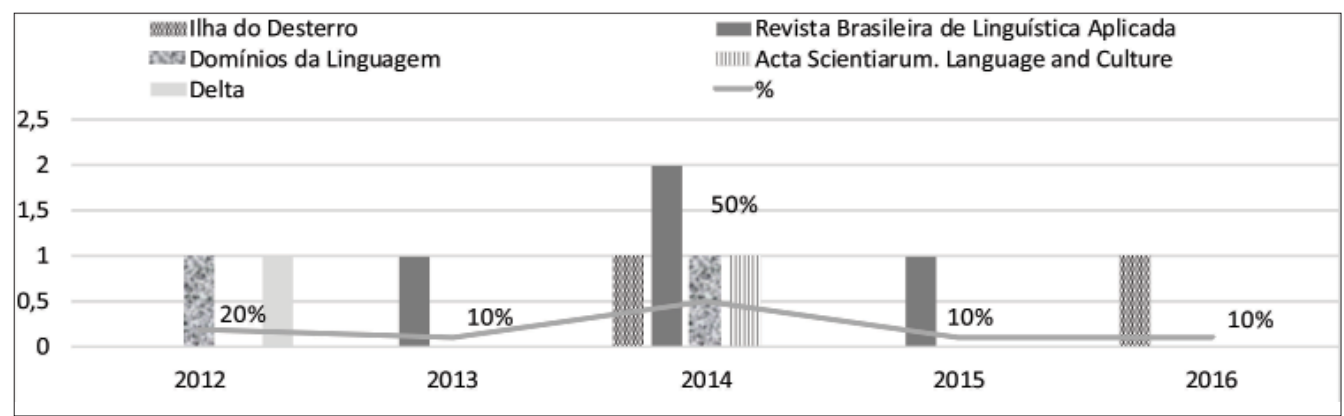

Figura 1 - Distribuição em percentual dos artigos por ano e por periódico. Fonte: Dados organizados pelas autoras.

Constata-se que em 2012 foram publicados dois artigos, representando $20 \%$, referentes à temática estudada, seguindo-se uma queda nas publicações em 2013, com 10\% nesse ano. Em 2014, há crescente elevação de publicações na temática de interesse, com $50 \%$ do total, seguida de queda significativa no ano de 2015, com 10\% mantida até maio de 2016. Em relação aos periódicos com maior número de publicações, destaca-se a Revista Brasileira de Linguística Aplicada com 40\%, seguida das revistas Ilha do Desterro e Domínios de Linguagem 20\% cada uma. Por fim as revistas Acta Scientiarum Language and Culture e Delta aparecem com $10 \%$ de publicações cada uma delas.

Pesquisas realizadas nas bases Scimago Journal Rank (SJR) e Domínios da Linguagem e Acta Scientiarum and Culture possibilitam confirmar uma quantidade significativa de publicações no ano de 2014 em comparação com os anos anteriores. O aumento do número de publicações nesse ano pode ter ocorrido 
pelo fato de ter sido aprovado o projeto do Plano Nacional de Ensino (PNE), somado ao evento da Copa do Mundo e das Olimpíadas de 2016. No entanto não há evidências suficientes que comprovem essa suposição, uma vez que os bancos de dados não distinguem Língua Inglesa da área de Letras.

Na Figura 2, apresenta-se a distribuição dos artigos por região de acordo com o vínculo institucional dos autores.

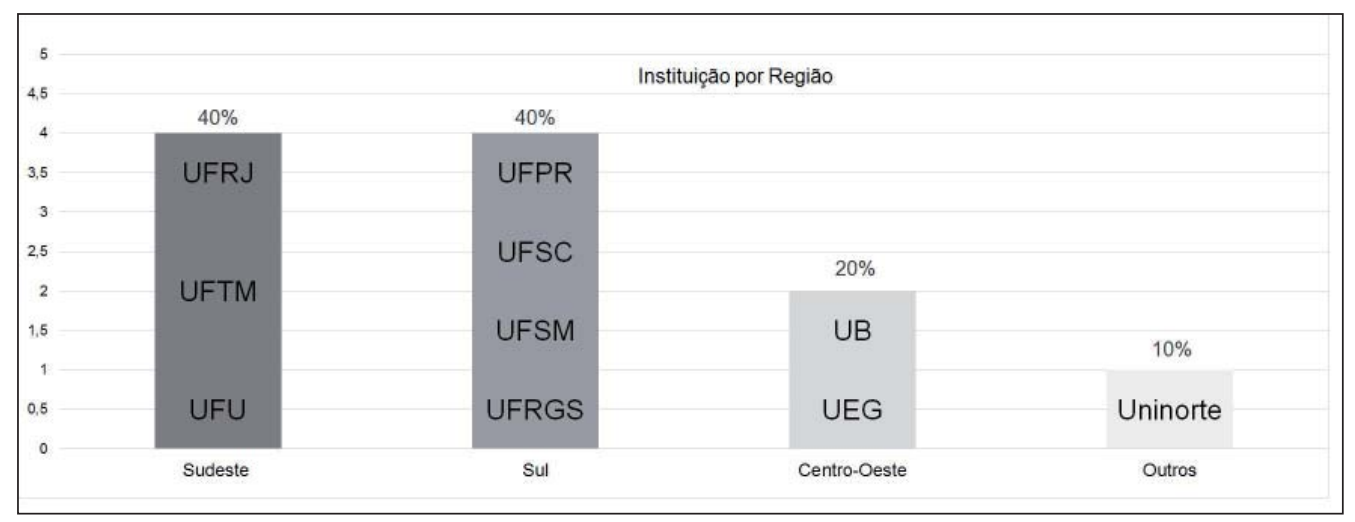

Figura 2 - Distribuição de artigos por região, conforme região de vínculo institucional

Fonte: Dados organizados pelas autoras

Da totalidade dos artigos analisados, quatro (40\%) foram produzidos por pesquisadores vinculados a instituições ou programas situados na região Sudeste do Brasil, um (10\%) da Universidade Federal do Rio de Janeiro (UFRJ), dois (20\%) da Universidade Federal do Triângulo Mineiro (UFTM) e um (10\%) da Universidade Federal de Uberlândia (UFU); quatro (40\%) foram produzidos por pesquisadores de instituições ou programas situados na região Sul do país com um (10\%) da Universidade Federal do Paraná (UFPR), um (10\%) da Universidade Federal de Santa Catarina (UFSC), um (10\%) da Universidade Federal de Santa Maria (UFSM) e um (10\%) da Universidade Federal do Rio Grande do Sul (UFRGS); dois (20\%) foram produzidos por pesquisadores de instituições ou programas da região do Centro-Oeste do país com um (10\%) produzido na Universidade de Brasília (UnB) e um (10\%) na Universidade Estadual de Goiás (UFG). Por fim, um único artigo (10\%) pertence a instituição internacional, a Universidad del Norte- Barranquilla (Uninorte) da Colômbia, representante de países internacionais com preocupa- 
ção nos processos ensino-aprendizagem de língua inglesa como segunda língua e que faz parte dos países que participaram do Congresso Mundial de Educação para Todos.

Notória é a participação das universidades federais em quantidade de publicações, totalizando sete das contribuições na área de estudos sobre o ensino de inglês no ensino fundamental. Destaque também para as regiões Sul e Sudeste que aparecem com oito das 10 publicações analisadas. Chama atenção a ausência de publicações nas regiões Norte e Nordeste do Brasil, em especial porque relatórios da Education First (EF EPI, 2015) apresentam dados como regiões de grande potencial turístico internacional e com níveis de proficiência na língua inglesa entre médio e baixo. Concordamos com a análise feita no Education First em que, embora se observe uma preocupação nos processos de ensino-aprendizagem para a melhoria da qualidade de ensino e o interesse pela aprendizagem do idioma nos principais polos socioeconômicos do país, é notório o desequilíbrio de interesses entre os estados brasileiros. A análise feita pela Education First (EF EPI, 2015) atribui esse desinteresse aos problemas de diferenças econômicas, aumentando ainda mais o abismo social entre os indivíduos da população, sejam eles do Norte, Nordeste do Brasil ou de países reconhecidos de alto índice de pobreza e problemas de ordem política, como é o caso da Colômbia. Fatores de políticas públicas educacionais deficientes também agravam esse abismo social e cultural.

Além disso, confirmam-se outras revisões de literatura sobre educação, a exemplo de Vieira e Souza (VIEIRA; SOUZA, 2012) quando tratam da constatação das desigualdades chamando a atenção para o fator de distribuição de renda e iniciativas de fomento de órgãos governamentais de incentivo à expansão e consolidação de programas de pós-graduação, principalmente de programas de doutorado. Em sua pesquisa sobre as publicações da Revista Brasileira de Educação (RBE), do período de 2007 a 2011, os autores referem-se aos estados com maiores publicações, os mesmos encontrados nesta pesquisa: Rio de Janeiro, Minas Gerais, Rio Grande do Sul, Paraná e Distrito Federal. No atual levantamento figuram também, Santa Catarina e Goiás.

Podemos ainda fazer uma correspondência entre as instituições de origem dos autores vinculados a programas de pós-graduação desse levantamento, e as do estudo de Vieira e Souza (VIEIRA; SOUZA, 2012), dentre as que mais se destacaram na produção acadêmica, como a Universidade Federal do Rio Grande do Sul 
(UFRS), a Universidade Federal do Rio de Janeiro (UFRJ), Universidade Federal de Minas Gerais (UFMG) e Universidade de Brasília (UnB), sugerindo a permanência de determinados polos nas publicações de pesquisas na área da educação, nesse caso, esta pesquisa apresenta como polo de estudo do tema a região Sudeste.

Vieira e Souza (VIEIRA; SOUZA, 2012) também fazem um alerta referente à internacionalização de artigos para a mobilidade de assuntos científica, tão discutida e induzida nos meios acadêmicos através de programas governamentais, como Ciências sem fronteiras e Inglês sem fronteiras, mas em que ainda não se percebe um número significativo de instituições, principalmente as da América do Sul, que tivessem interesse na interlocução de assuntos educacionais. Com a globalização, a internacionalização de produções científicas no meio acadêmico como meio de intercâmbio de conhecimento se faz necessário e a língua utilizada de entendimento em comum é o inglês por dominar os campos da tecnologia e pesquisas científicas. Segundo Finardi e França (2016), o número de publicações brasileiras em periódicos com bases indicadoras internacionais não passa de 1\% em relação às publicações mundiais. Esse número só aumenta quanto se trata de publicações nacionais. A alta exigência como requisitos para requerer recursos de auxílio a produções científicas são consideradas uma problemática, uma vez que as instituições devem manter pesquisas vinculadas a FAPESP, e o periódico de interesse de publicação deve ter, como indexador para a publicação das pesquisas, bases como Scopus, ISI, PubMed e SciELO. Esse fato acaba por restringir o tipo de instituição beneficiária, que em sua maioria são as instituições federais as escolhidas para os repasses de verba.

Uma leitura minuciosa dos títulos, resumos e palavras-chave possibilitou a identificação das subtemáticas abordadas nos artigos selecionados, as quais se apresentam na Figura 3. 


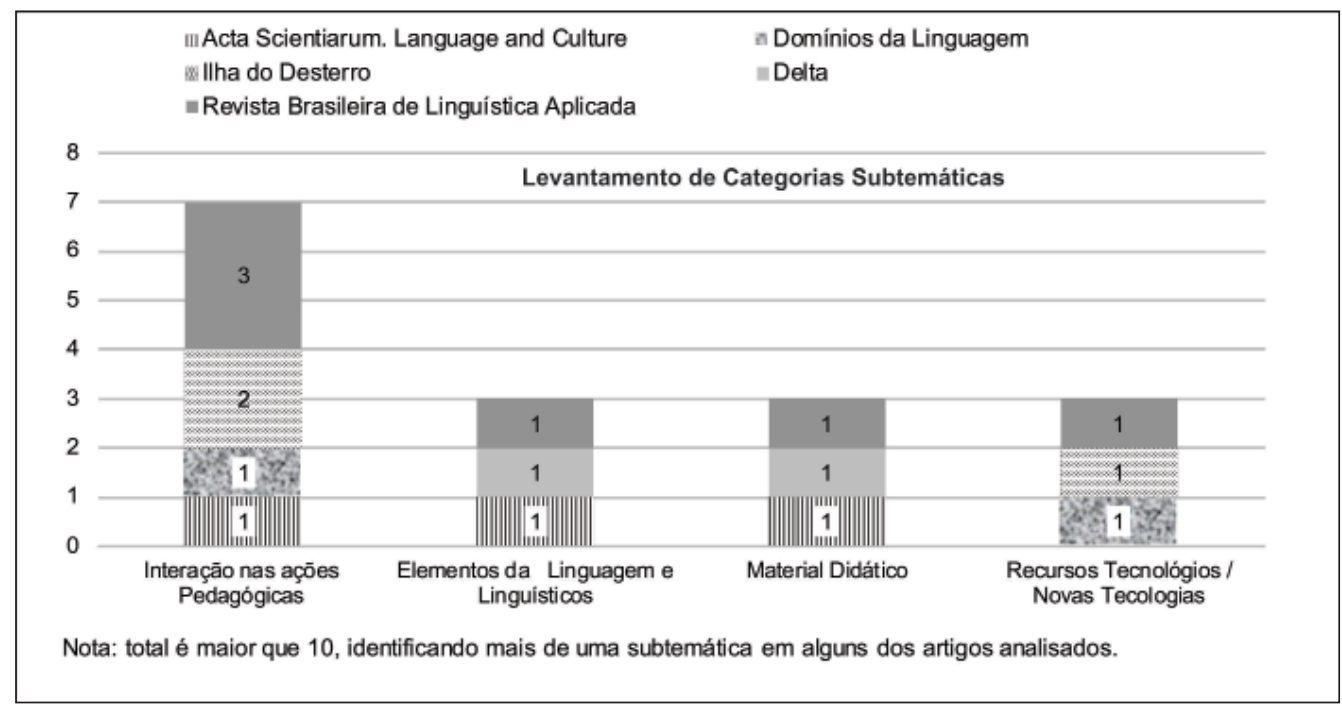

Figura 3 - Distribuição em números absolutos das principais subtemáticas abordadas Fonte: Dados organizados pelas autoras.

Os dados apontam uma ênfase na subtemática Interação nas ações pedagógicas, constituída por conteúdos relativos às práticas sociais, atividades colaborativas, interações e mediações nas ações pedagógicas, em sete dos 10 artigos selecionados, sendo três da Revista Brasileira de Linguística Aplicada, os de Silvestre (2015), Tavares e Oliveira (2014) e Vilas Boas (2014); dois da Revista Ilha do Desterro com artigos de Bolzan e Spinassé (2016) e Tumolo (2014), um da Revista Domínios de Lingu@gem com artigo de Silveira (2012) e um da Acta Scientiarum and Culture com artigo de Marques e Marques (2014). A Revista Brasileira de Linguística Aplicada foi o periódico que mais publicou com foco nesse subtema, provavelmente porque seu objetivo é a divulgação de artigos que tratam dos assuntos relacionados à linguagem em diferentes situações e contextos de uso e de ensino e os problemas relacionados com os processos ensino-aprendizagem.

A subtemática denominada Elementos da Linguagem e Linguísticos refere-se a conteúdos relativos à concepção de língua analisada sob os aspectos culturais e ideológicos e os significados que estabelecem relações de poder entre textos e leitores; e à visão de língua como constructo idealizado e desvinculado da realidade. São três artigos nessa subtemática, sendo um da Revista Brasileira de Linguística Aplicada, de Vilas Boas (2014), um da Revista Delta, com artigo de 
Jordão e Fogaça (2012), e um da Revista Acta Scientiarum Language and Culture, no artigo de Marques e Marques (2014).

A subtemática denominada Material Didático coloca como ênfase os recursos pedagógicos criados ou desenvolvidos para o ensino-aprendizagem de língua inglesa, em três artigos, como produção e análise de material didático, um da Revista Brasileira de Linguística Aplicada, de Villa Boas (2014), um da Revista Delta, de Jordão e Fogaça (2012) e um da Revista Acta Scientiarum Language and Culture, de Marques e Marques (2014).

Por fim, a subtemática denominada Recursos Tecnológicos como ferramenta do processo ensino-aprendizagem, constituiu-se dos conteúdos sobre as novas tecnologias no ensino da língua inglesa, em três artigos, um da Revista Brasileira de Linguística Aplicada, de Tavares e Oliveira (2014), um do periódico Ilha do Desterro, de Tumolo (2014) e um da revista Domínios de Lingu@gem, de Silveira (2012).

Em relação às análises de aporte teórico, foi necessário adentrar as leituras de cada publicação. Levou-se em consideração o aporte teórico mencionado, as áreas de conhecimento e as referências para se estabelecer ou não aproximações ao sociointeracionismo. O objetivo era identificar teorias de aprendizagem explicitadas em cada artigo. As análises resultaram em quantidade reduzida de artigos com essa explicitação, talvez pelo fato de os periódicos onde se localizam as publicações não serem da área da educação ou da psicologia da educação, e sim, da área de linguagem.

Embora os conceitos de mediação e interação possam ser associados de forma indireta em pelo menos oito dos dez artigos selecionados, apenas dois trazem citações às teorias de Vigotsky, como é o caso do artigo de Bolzan e Spinassé (2016) e de Marques e Marques (2014). No primeiro, o conhecimento se dá através da interação entre pares na produção de textos e, no segundo, analisam-se avaliações e o processo ensino-aprendizagem decorrentes de resultados obtidos, sendo apontadas falhas nas práticas em sala de aula, com destaque para os processos que resultam das interações entre professor-aluno.

Os artigos de Bolzan e Spinassé (2016) e Vilas Boas (2014) analisam as relações entre os indivíduos durante uma atividade colaborativa na prática da escrita em processo ensino-aprendizagem de língua inglesa e as reações decorrentes da interação entre os pares. Os resultados são positivos nas expressões dos alunos, e é possível estabelecer uma aproximação com a abordagem sociointeracionista 
pela ênfase dada ao processo de interação entre os sujeitos e as contribuições sociais e culturais decorrentes da interação.

Nos artigos de Silvestre (2015) e Jordão e Fogaça (2012), os estudos apontam para vivências práticas no contexto escolar ancoradas numa perspectiva crítica de Paulo Freire. Em Silvestre (2015), a prática está relacionada ao papel do agenciamento docente e das expectativas de ensino vivenciadas no contexto escolar. Segundo Pereira (2013), tal "agenciamento" refere-se aos diferentes papéis sociais exercidos em ambientes em constantes mutações e de interações com diversos tipos de sujeitos. Nos estudos de Silvestre (2015), o termo "agenciamento" seria a condução das atividades aplicadas pelo mediador do processo ensino-aprendizagem, levando em conta as condições locais de vida dos alunos, o material disponível para o desenvolvimento das atividades e a contemplação do conteúdo em relação ao currículo. A maneira como tudo isso é conduzido pelos professores durante o projeto relatado resulta em conhecimento, participação, visão de novos contornos da realidade, trânsito na diversidade e reflexão sobre o mundo. Em Jordão e Fogaça (2012), a concepção de linguagem como aporte teórico, no letramento crítico, coloca os alunos como coprodutores de significados e sentidos à língua. A interação é analisada a partir da relação entre aluno e material didático desenvolvido e a ação do mediador que se utiliza de instrumento - o material didático- como facilitador da aprendizagem.

Ainda segundo Jordão e Fogaça (2012), ao teorizar a pesquisa, citam que trabalhar textos orais e escritos no ensino de línguas estrangeiras possibilita a reflexão sobre questões significativas para a vida dos alunos contribuindo para que ampliem o entendimento sobre eles próprios e sobre o mundo em que vivem. Os autores ressaltam o entendimento de que tais atividades dão condições aos alunos de exercerem as práticas sociais de leitura e de escrita que circulam na sociedade em que vivem, conjugando-as com as práticas sociais de interação oral. Nessa visão, ser crítico requer a percepção de que os textos estão ancorados nos contextos discursivos em que são produzidos, onde crenças e valores são sócio-historicamente construídos nesses contextos. As práticas de letramento deixam de ser apenas a língua como discurso, pelo qual se ensina e aprende um código e como decifrá-lo, e passam a ser entendidas como discursos construídos pelo uso social da língua, um sistema complexo de produção de sentidos que constrói significados em práticas ideológicas. Na visão dos autores, a língua como produto 
de uma sociedade é a representatividade dos vários tipos de linguagem, caracterizada pelos discursos através de textos, e o letramento é o uso desses textos em contextos sociais de forma significativa. Para os autores, aprender de forma significativa é saber usar as ferramentas necessárias para pôr em prática o discurso. A construção do conhecimento a partir de algo que tenha significado pode gerar sentidos presente nos discursos de cada sujeito. A esses sentidos os autores citam Foucault sobre a subjetividade presente na linguagem. A subjetividade, que é o sentido subjetivo produzido por cada indivíduo, aliado ao letramento, fornece ao sujeito possibilidades de produção de crítica de mundo e de si mesmo. Nessa perspectiva, os sujeitos ocupam lugar de representante social e suas identidades. A essa perspectiva os autores denominam de Letramento Crítico.

Embora apenas nos PCNs para o Ensino Médio (BRASIL, 2002) haja menção explícita sobre o ensino com enfoque no letramento crítico, os autores acreditam que o ensino sociointeracionista possa ser complementado com ideias do letramento crítico, uma vez que, numa educação sociointeracionista, os sujeitos interagem entre si e com o objeto do conhecimento construindo significados conforme suas experiências de história e cultura, agindo no mundo e sofrendo a ação dele. Essas ideias contribuem para a ideia de leituras de mundo através do letramento, e os vários sentidos desenvolvidos de forma crítica no processo de aprendizagem, através do letramento crítico, ajudam os sujeitos no exercício pleno de sua cidadania. Atualmente a Base Nacional Comum Curricular (BNCC) (BRASIL, 2017) recentemente homologada, vai de encontro esse pensamento, ao mencionar o termo agenciamento crítico dos estudantes para o exercício da cidadania ativa, no que concerne o ensino de Língua Inglesa o Ensino Fundamental. Embora os documentos oficiais não explicitassem uma ideia de letramento crítico para o Ensino Fundamental, muitos professores tendiam para essa prática em sala de aula, até mesmo porque muitos livros didáticos vêm seguindo essa tendência.

Os artigos de Marques e Marques (2014) e Machado (2014) também apontam para um tipo de perspectiva crítica que conduz a uma aproximação sociointeracionista, como a interação entre os sujeitos durante processo ensino-aprendizagem e a representação social sobre a noção de ensino e afastamento discursivo frente a esses elementos. Em Marques e Marques (2014) o estudo propõe analisar a forma como são conduzidas as avaliações, as quais, de acordo com as diretrizes curriculares, devem ser contextualizadas, a linguagem concebida 
como interação, o que implica uma mudança de postura dos docentes da educação básica. Os instrumentos de avaliação, na prática, devem se adequar a uma perspectiva discursiva (interacionista) e buscar uma correspondência do conteúdo com o mundo e a vida prática, considerando a faixa etária do aluno, que reflete sobre seus atos ao agir. Machado (2014), em seus estudos com alunos de uma escola pública, analisa resultados que levam a crer que existem elementos específicos nos discursos dos alunos comprometidos com a reprodução idêntica dos discursos socialmente estruturados sobre o ensino de língua inglesa. A análise desses elementos qualifica a linguagem como uma forma de representação social. Segundo Pereira (2013), a análise do discurso contribui na descrição do fenômeno da linguagem atravessada por aspectos das práticas políticas e ideológicas, sendo a ideologia manifestada nos sentidos produzidos nas relações de poder. Observam-se, nesse caso, que os textos são lugares de conflito à medida que mostram diferentes discursos e ideologias em disputa e em conflito por domínio.

Também os artigos de Rosado (2013) e Silveira (2012) analisam essa questão, com aporte teórico no paradigma da complexidade, com referência a Morin, para compreender a aprendizagem como um sistema complexo ao abordar a aprendizagem dos alunos por meio de uma perspectiva recursivamente associada à aprendizagem dos professores. O destaque nas análises coloca em evidência as atitudes do mediador que pode influenciar de maneira positiva ou negativa o processo ensino-aprendizagem da língua inglesa. Guardadas as devidas distâncias entre o paradigma da complexidade e a abordagem sócio-histórica, apreendemos uma aproximação na consideração de González sobre a "integração complexa entre o social e o individual no desenvolvimento social"; em outra passagem, o autor destaca que "os discursos como sistema semióticos de natureza social são importantes, não como um fim em si mesmo, mas como via que nos permite a construção de dimensões ocultas do social" (GONZÁLEZ REY, 2005, p. 213).

Os textos de Tumolo (2014), Tavares e Oliveira (2014) e Silveira (2012) têm aportes teóricos diversificados, mas em todos há a presença do professor como mediador e motivador das interações realizadas através de novas tecnologias. O artigo de Tavares e Oliveira (2014), ancorado no aporte teórico que trata da inclusão na Educação Especial, utiliza-se das novas tecnologias como facilitadora do processo ensino-aprendizagem, podendo-se afirmar sobre uma aproximação com a abordagem sociointeracionista pela análise das mediações entre professor, 
aluno e instrumento e pelas práticas realizadas através da interação entre aluno-computador, confirmando que os instrumentos são importantes mediadores de novos processos mentais.

Não se pretende, com esta breve análise, fazer um reducionismo dos aportes teóricos originais apontados pelos autores dos artigos selecionados para análise, no entanto o que se quer trazer à tona é a quase ausência de discussões pautadas por autores da psicologia da educação na reflexão dos processos de ensino-aprendizagem. A opção pelo aporte da teoria sociointeracionista se deve ao fato de que Vigotsky $(1991 ; 1996)$ concebeu uma representação da psique humana como um sistema complexo e em constante desenvolvimento, nos espaços sociais e culturais onde os sujeitos se relacionam. Esse princípio é fundamental para se considerar a importância dos processos de ensino-aprendizagem, sobremaneira os que ocorrem nos espaços legitimamente constituídos para o ensino e a aprendizagem de crianças e jovens, que necessitam ser investidos para se tornarem de fato em espaços significativos da promoção de educação de qualidade.

Considera-se que a exiguidade de artigos publicados sobre a temática do ensino da língua inglesa para o ensino fundamental pode ser um indicador da pouca importância que se tem dado para o debate do letramento crítico da população de alunos que frequentam as escolas, em especial, as públicas, o que inclui não só o debate da alfabetização na língua materna, mas também em uma segunda língua.

\section{CONCLUSÃO}

A relevância de estudos de revisão de literatura refere-se à produção de um conhecimento a partir do qual se pode fazer reflexões e tomar decisões ou apontar saídas para os problemas, o que vale sobremaneira para o âmbito da educação.

O aporte teórico sociointeracionista assumido nesta análise tem como foco reconhecer o homem como ser social e que desenvolve suas potencialidades nas interações com seus pares no meio social e cultural. O processo de aprendizagem de uma segunda língua traz à tona a importância da linguagem como instrumento de humanização, em um mundo globalizado, em que apenas a língua materna deixa de ser suficiente para entrar "em um mundo de significações que é construído no processo social e histórico" (AGUIAR, 2001, p. 204). Assim, além de se 
levar em conta o aspecto social, pois o homem necessita interagir com o outro, levam-se em conta os aspectos culturais. Esses aspectos contribuem para o desenvolvimento intelectual do homem, que se utiliza das palavras para expressão de seus pensamentos. Expressão esta realizada através dos signos.

Em muitos dos artigos analisados, as atividades de comunicação propostas colocavam em foco a figura de um mediador, o professor, que estrategicamente dispunha de situações de interação entre os alunos através de signos linguísticos, sendo este um instrumento do conhecimento. Tão importante quanto a mediação, nos artigos analisados ressalta-se a interação como um processo que se realiza no discurso permeado pelo modo de pensar e agir no mundo, configurando interações por vezes equivocadas.

Constata-se que as práticas analisadas, resultantes de diferentes processos de mediação, quer pela revisão de pares para a produção escrita, quer na relação dialogada entre professor-aluno, quer pela oportunização da relação aluno-computador, são indícios de uma preocupação em relação aos processos de ensino-aprendizagem para melhoria na qualidade de ensino.

$O$ atendimento às solicitações da Unesco, em conferência realizada em 1990, e ao Plano Nacional de Educação, lançado em 2014 em consonância com os propósitos estabelecidos pela Unesco, requer uma ampla mobilização de todos em prol de uma educação de qualidade, o que implica também, o alinhamento das práticas pedagógicas e dos recursos disponibilizados aos alunos. Ainda que, na maioria dos artigos analisados, os autores não explicitem diretamente a teoria sociointeracionista, as reflexões sobre as práticas de ensino sugerem aproximações com essa abordagem, bem como com uma perspectiva de ensino crítico, ancorada no fundamento da pedagogia crítica.

Se levarmos em conta os rumos da educação que temos hoje, acreditamos que uma abordagem complemente a outra, uma vez que ambas se preocupam com a construção do sujeito como ser social praticante e atuante, um ser capaz de mudar sua realidade através da reflexão e do conhecimento. Tão importante de acordo com o aporte teórico apontado nos documentos oficiais, é a condução do processo ensino-aprendizagem por uma pedagogia crítica orientada na construção da cidadania pelo acesso a outras culturas e ideologias. No caso do ensino da língua inglesa, já estamos perdendo terreno na inserção de nossos alunos como cidadãos para o mundo globalizado. 
Quanto a soluções para a resolução de problemas, acreditamos que os investimentos lançados para a qualificação de professores devem ser constantes e que medidas de mobilização entre culturas devem ser incentivadas.

Conforme já mencionado em Declaração de Nova Delhi (UNESCO, 1993), a educação brasileira deve rever constantemente os documentos que regulam a educação no intuito de encontrar soluções para a melhoria da qualidade de ensino, seja na reestruturação dos conteúdos que devem fazer parte de cada componente curricular, quer nas metodologias que possam ser aplicadas de modo eficiente, visto que um dos problemas referentes ao ensino de línguas estrangeiras refere-se à formação do professor e às dificuldades que este tem, quanto ao processo ensino-aprendizagem, em desenvolver práticas pedagógicas que alinhem teoria à prática.

Atualmente é discutida a reforma do Ensino Médio, na qual se propõe o ensino baseado em áreas do conhecimento. A despeito das críticas e dos debates que tal reforma vem proporcionando, o que é saudável para o desenvolvimento da sociedade, no que tange ao ensino de língua inglesa, ele é proposto como obrigatório desde o sexto ano do Ensino Fundamental, segundo a proposta da nova Base Nacional Comum Curricular. Entendemos que essa proposta venha a atender às necessidades da sociedade, responsabilizando as escolas em formar cidadãos do mundo, não apenas na construção de um conhecimento pautado por parâmetros sociais, históricos e culturais, bem pelo desenvolvimento do pensamento crítico que leve a uma construção identitária dos envolvidos.

\section{REFERÊNCIAS}

AGUIAR, Wanda Maria Junqueira. Consciência e atividade: categorias fundamentais da psicologia sócio-histórica. In: BOCK, Ana Mercês Bahia; GONÇALVES, Maria da Graça Marchina; FURTADO, Odair (Org.). Psicologia sócio-histórica: uma perspectiva crítica em psicologia. São Paulo: Cortez, 2001.

BARDIN, Laurence. Análise de conteúdo. Lisboa: Edições 70, 1977.

BOLZAN, Daniele Blos; SPINASSÉ, Karen Pupp. A percepção de jovens aprendizes de segunda língua em relação á prática de revisão por pares em produção escrita. Ilha do Desterro, Florianópolis, v. 69, n. 1, p. 95-110, jan./abr. 2016.

BRASIL, Ministério da Educação. Secretaria de Educação Básica. Base Nacional Comum Curricular-BNCC. Brasília: MEC/SEB, 2017. 
- Ministério da Educação. Secretaria de Articulação com os Sistemas de Ensino. Planejando a próxima década: conhecendo as 20 Metas do Plano Nacional de Educação. Brasília: MEC/SASE, 2014.

. Secretaria de Educação. Parâmetros Curriculares Nacionais (Ensino Médio). Orientações Educacionais Complementares aos Parâmetros Curriculares Nacionais. Linguagens, Códigos e suas Tecnologias. Brasília: MEC/SEF, 2002. 241p.

. Secretaria de Educação. Parâmetros Curriculares Nacionais (Ensino Médio). Parte II-Linguagens, Códigos e suas Tecnologias. Brasília: MEC/SEF, 2000. 71p.

. Secretaria de Educação Fundamental. Parâmetros curriculares nacionais: terceiro e quarto ciclos do ensino fundamental: língua estrangeira. Brasília: MEC/SEF, 1998. 120p.

. Ministério da Educação. Lei n. 9.394, 20 de dezembro de 1996. Lei de Diretrizes e Bases da Educação Nacional. Brasília, DF, 1996. Disponível em: <http://www.planalto. gov.br/Ccivil_03/leis/L9394.htm>.

BRITISH COUCIL. O Ensino de Inglês na Educação Pública Brasileira. Elaborado com exclusividade para o British Council pelo Instituto de Pesquisas Plano CDE. 1. ed. São Paulo, 2015. Disponível em: <https://www.britishcouncil.org.br/sites/default/files/ estudo_oensinodoinglesnaeducacaopublicabrasileira.pdf>. Acesso em: 19 maio 2016.

. Demandas de aprendizagem de inglês no Brasil. Elaborado pelo Instituto de Pesquisa Data Popular. 1. ed. São Paulo, 2013. Disponível em: <https://www.britishcouncil. org.br/pesquisas-infograficos>. Acesso em: 19 maio 2016.

DANIELS, Harry. Vygotsky e a Pedagogia. Tradução de Milton Camargo Mota. São Paulo: Edições Loyola, 2003.

DELORS, Jacques. Educação: um tesouro a descobrir. 7. ed. São Paulo: Cortez; Brasília, DF: Unesco, 2012.

EDUCATION FIRST ENGLISH PROFICIECY INDEX (EF EPI). Índice de proficiência em inglês da EF. Education First, 2015. Disponível em: <http://mediaefcomstatic-681.kxcdn.com/_ / / media/centralefcom/epi/downloads/full-reports/v5/ef-epi-2015-portuguese.pdf $>$. Acesso em: 23 maio 2016.

FINARD, Kyria Rebeca; FRANÇA, Claudio. O inglês na internacionalização da produção científica brasileira: evidências da subárea de linguagem e linguística. Intersecções, Jundiaí, SP, ed. 19, ano 9, n. 2, p. 234-50, maio 2016.

GONZÁLEZ REY, Fernando Luis. Sujeito e subjetividade: uma aproximação históricocultural. Tradução de Raquel Souza Lobo Guzzo. São Paulo: Pioneira Thomson Learning, 2005.

JORDÃO, Clarissa Menezes; FOGAÇA, Francisco Carlos. Critical literacy in the english language classroom. Delta, São Paulo, v. 28, n. 1, p. 69-84, 2012. 
MACHADO, Éderson Henrique de Sousa. Discurso sobre ensino de língua inglesa e gramática sistêmico-funcional. Domínios de Lingu@gem, Uberlândia, MG, v. 8, n. 1, p. 316-40, jan./jun. 2014.

MARQUES, Welisson; MARQUES, Dóris Day Rodrigues. Avaliação (des)contextualizada de língua inglesa no ensino fundamental - a distância entre teoria e prática. Acta Scientiarum. Language and Culture, Maringá, PR, v. 36, n. 2, p. 183-93, abr./jun. 2014.

MORAES, Roque. Análise de conteúdo. Revista Educação, Porto Alegre, RS, v. 22, n. 37, p. 7-32, 1999.

ORGANIZAÇÃO DAS NAÇÕES UNIDAS PARA A EDUCAÇÃO, A CIÊNCIA E A CULTURA (UNESCO). Declaração de Nova Delhi sobre educação para todos. In: Meeting of the international Consultative Forum on Education for all $2^{\text {nd }}$. Nova Delhi, Índia, 6-12-1993. Disponível em: <http://unesdoc.unesco.org/images/0013/001393/139393por.pdf>. Acesso em: 9 out. 2016.

Secretariat of the International Consultative Forum on Education for All (2012). World Declaration on Education for all and framework or action to meet basic learning needs. In: WORLD CONFERENCE ON EDUCATION FOR ALL. Meeting Basic Learning Needs. Jomtien, Thailand, 5-9 mar. 1990. Disponível em: <http://unesdoc.unesco.org/ images/0012/001275/127583e.pdf>. Acesso em: 24 set. 2016.

PEREIRA, Paula. Graciano. Docência em língua inglesa nas perspectivas crítica e sóciohistórico-cultural: as experiências de dois alunos professores em formação inicial na disciplina de estágio supervisionado. 2013. xvii, 263f. Tese (Doutorado em Letras e Linguística) - Universidade Federal de Goiás (UFG), Goiânia, GO, 2013.

RIOS, Terezinha Azeredo. Compreender e ensinar: por uma docência da melhor qualidade. 4. ed. São Paulo: Cortez, 2003.

ROSADO, Nayibe. Instanciação da complexidade da aprendizagem de alunos e professores na sala de aula de inglês como língua estrangeira. Revista Brasileira de Linguística Aplicada - RBLA, Belo Horizonte, MG, v. 13 n. 2, p. 399-436, 2013.

SCIMAGO JOURNAL \& COUNTRY RANK (SJR). Disponível em: <http://www.scimagojr.com/

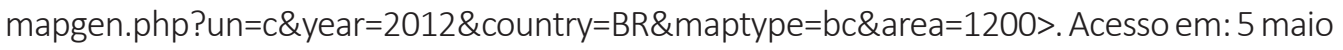
2016.

SILVEIRA, Larissa de Sousa. Ensino e aprendizagem de língua inglesa e recursos tecnologógicos: um estudo sobre os processos de retroação e reversibilidade. Domínios de Lingu@gem, Uberlândia, MG, v. 6, n. 2, p. 19-40, 2012.

SILVESTRE, Viviane Pires Viana. Ensinar e aprender língua estrangeira/ adicional na escola: a relação entre perspectivas críticas e uma experiência prática localizada. Revista Brasileira de Linguística Aplicada-RBLA, Belo Horizonte, MG, v. 15, n. 1, p. 61-84, jan./ mar. 2015. 
TAVARES, Kátia Cristina do Amaral; OLIVEIRA, Ana Paula Pires de. Libras no ensino de inglês mediado pelas novas tecnologias: desafios e possibilidades. Revista Brasileira de Linguística Aplicada-RBLA, Belo Horizonte, MG, v. 14, n. 4, p. 1045-72, out./dez. 2014.

TUMOLO, Celso. Recursos digitais e aprendizagem de inglês como língua estrangeira. I/ha do Desterro, Florianópolis, n. 66, p. 203-38, jan./jun. 2014.

VIEIRA, Carlos Eduardo; SOUZA, Sandra Zákia. A Revista Brasileira de Educação e a difusão da pesquisa educacional (2007-2011). Revista Brasileira de Educação, v. 17, n. 50, p. 463-82, maio/ago. 2012.

VILAS BOAS, Isabela de Freitas. Produção textual como um processo em um contexto centrado no produto: desafios e possibilidades. Revista Brasileira de Linguística Aplicada - RBLA, Belo Horizonte, MG, v. 14, n. 2, p. 463-90, abr./jun. 2014.

VYGOTSKI, Lev Semyonovich. Pensamento e linguagem. Tradução de Jefferson Luiz Camargo. São Paulo: Martins Fontes, 1996.

. A formação social da mente. Tradução de José Cipolla Neto, Luis Silveira Menna Barreto e Solange Castro Afeche. 4. ed. São Paulo: Martins Fontes, 1991.

\section{Sobre as autoras:}

Cristielaine Aparecida Alves de Souza: Mestranda em Psicologia Educacional e Especialista em Psicopedagogia Clínica e Institucional pelo Centro Universitário Fieo (Unifieo). Docente de Inglês Técnico para cursos de Tecnologia e Engenharias no Centro Universitário FIEO; Professora por 10 anos na rede pública de São Paulo; Professora de inglês em cursos livres. Docente dos componentes curriculares Português, Literaturas e Comunicação Profissional e Inglês Instrumental para Ensino Médio no Centro Paula Souza e tutora de estágio supervisionado em curso de letras Inglês. E-mail: cristielaine.souza@uol.com.br

Marisa Irene Siqueira Castanho: Pós-doutorado em Educação pelo Programa de Pós-Graduação em Educação da Universidade Nove de Julho (PPGE-UNINOVE), São Paulo. Doutora e Mestre em Psicologia Escolar e do Desenvolvimento Humano pelo Instituto de Psicologia da USP (IPUSP), São Paulo. Docente e pesquisadora do Programa de Pós-Graduação em Psicologia Educacional do Centro Universitário Fieo (Unifieo), Osasco, SP. E-mail: msiqueiracastanho@gmail.com

\section{Recebido em agosto de 2017 Aprovado em fevereiro de 2018}


